\section{AB0072 RATIONAL DESIGNED GOLD NANOPARTICLE SUPPRESSES RANKL-INDUCED OSTEOCLASTOGENESIS IN RAW264.7 CELLS VIA NF-KAPPA B PATHWAY AND MAPK PATHWAYS}

Q. Yuan ${ }^{1,2}$, X. Gao ${ }^{1,2},{ }^{1}$ Key Laboratory for Biological Effects of Nanomaterial and Nanosafety, Institute of High Energy Physics, CAS; ${ }^{2}$ Department of Chemistry and Chemical Engineering, Beijing University of Technology, Beijing, China

Background: Bone erosion in joint is the most deleterious effect induced by rheumatoid arthritis (RA) and is the major cause of disability. New therapies are urgently required to prevent RA-associated bone destruction. The excessive bone resorption in RA was proved to be mediated by osteoclasts which are derived from the monocyte/macrophage lineage and induced by RANKL. Therefore, RANKL could be a potential target for the preservation of bone mass in RA.

Objectives: Chrysotherapy showed potential effects in reducing of joint destruction but with serious side-effects in RA therapy. A rational designed gold nanoparticle named GN was prepared to provide a choice for suppressing bone loss in RA therapy with more safety.

Methods: Mice macrophage cell line RAW264.7 was activated by RANKL to evaluate the potential osteoclastogenesis suppressing effects of GN. The differentiation, fusion and function of osteoclast were assessed by tartrateresistant acid (TRAP) staining, actin ring formation assay and osteologic discs detection respectively. Relative expressions of osteoclast-specific genes were evaluated by RT-PCR and the activity of NF-KB pathway as well as MAPK pathways were analyzed by immunoblotting

Results: Osteoclast differentiation, fusion and bone resorption were activated by RANKL in RAW264.7 cell, while GN significantly attenuates this process in a dose-dependent manner. The expressions of osteoclast-specific genes including TRAP and OSCAR were increased by RANKL stimulation but were effectively suppressed by GN. The activation of NF-kappa B pathway and MAPK pathways induced by RANKL was also suppressed by GN treatment.

Conclusions: Our findings revealed that treatment with GN could prevent RANKLinduced osteoclastogenesis and reduce increased expression of osteoclastspecific genes which may through the suppression of NF-kB and MAPK activation in macrophage. GN may provide a basis for the design of chrysotherapy drugs that effect in progression of RA-associated articular erosions.

Disclosure of Interest: None declared

DOI: 10.1136/annrheumdis-2017-eular.2087

\section{AB0073 ACCUMULATION OF ADVANCED GLYCATION END PRODUCTS (AGES) IN OSTEOARTHRITIC CARTILAGE IS RELATED TO AN IMPAIRMENT OF THE ADAPTATIVE MECHANISM OF GLYOXALASE-1}

S. Trellu ${ }^{1}$, A. Courties ${ }^{1}$, S. Jaisson ${ }^{2}$, B. Friguet ${ }^{3}$, X. Houard ${ }^{4}$, F.-P. Ehkirch ${ }^{5}$ C. Jacques ${ }^{4}$, F. Berenbaum ${ }^{1}$, J. Sellam ${ }^{1} .1{ }^{1}$ UPMC Univ Paris 06, Inserm UMRS_938, Rheumatology department, AP-HP, Saint-Antoine Hospital, Paris; 2 University of Reims Champagne-Ardenne, UMR CNRS 7369, Laboratory of Biochemistry and Molecular Biology, Reims; ${ }^{3}$ UPMC Univ Paris 06, UMR 8256, Biological Adaptation and Ageing-IBPS: ${ }^{4}$ UPMC Univ Paris 06, Inserm UMRS 938, Saint-Antoine Hospital: 5 Groupe Maussins, Clinique des Maussins-Ramsay, Général de Santé, Paris, France

Background: Advanced glycation end-products (AGEs) that result from a nonenzymatic reaction between a sugar and a protein, are generated during tissular ageing. Accumulation of AGEs could also be part of the osteoarthritis (OA) process by modifying the biomechanic properties of cartilage and by inducing chondrocyte activation. Glyoxalase-1 (Glo-1) is the main enzyme involved in the removal of AGEs precursors, especially the AGE carboxymethyllysine (CML).

Objectives: We aimed to quantify CML in human osteoarthritic cartilage, to investigate Glo-1 expression in chondrocytes and to study chondrocytic Glo-1 regulation in an inflammatory context.

Methods: 1) Ex vivo: Osteoarthritic cartilages from patients undergoing knee replacement were collected, dissected and incubated for 24h with or without IL-1 $\beta(5 \mathrm{ng} / \mathrm{ml})$. We quantified CML in these cartilage explants using liquid chromatography and mass spectrometry, Glo-1 protein expression (Western Blot and immunohistochemistry) and Glo-1 enzymatic activity by measuring the kinetic of formation of the Glo-1 product (S-D lactoylglutathione) using spectrophotometry at $240 \mathrm{~nm}$ during 10 minutes. 2) In vitro: Primary cultured murine chondrocytes (C57B6) were stimulated $72 \mathrm{~h}$ with increasing IL-1 $\beta$ doses (0 to $10 \mathrm{ng} / \mathrm{mL}$ ). Glo-1 expression was assessed by quantitative RT-PCR, Western blot and enzymatic activity. To analyze whether oxidative stress is involved in Glo-1 regulation induced by IL-1 $\beta$, cells were treated with inhibitors of mitochondrial oxidative stress (MitoTEMPO) or of nitric oxide (NO) synthase (L-NAME)

Results: 1) Ex vivo, CML was found in all human OA cartilage samples and its level increased according to age (correlation coefficient CML/age: $r=0.78, p<0.01$ ). In parallel to CML increase, Glo-1 protein was expressed in chondrocytes on all layers of cartilage. A positive correlation was found between Glo- 1 enzymatic activity and the age of the patients $(r=0.45, p<0.05)$ but was lost in case of incubation with IL-1 $\beta$ ( $r=-0.09$, $p$ non significant). 2) In vitro, in murine chondrocytes cultures, we observed a dose-dependent decrease of IL1 $\beta$-induced Glo-1 mRNA ( 0.67 fold, $p<0.05)$, protein quantity $(0.56$ fold, $p<0.05)$ and enzymatic activity $(0.7$ fold, $p<0.05)(n=5)$. The blockade of NO by L-NAME, and of mitochondrial oxidative stress by MitoTEMPO counteracted the downregulation of IL1 $\beta$-induced Glo- 1 expression and enzymatic activity $(n=5)$.

Conclusions: We show here that the age-dependent accumulation of AGEs in OA cartilage could be due to an impairment of the adaptative mechanism of Glo-1, mediated by oxidative stress. Further studies aiming at targeting Glo-1 restauration as a therapeutical strategy for ageing-related $O A$ are needed.

Disclosure of Interest: None declared DOI: 10.1136/annrheumdis-2017-eular.1452

\section{AB0074 INFLUENCE OF COBALT AND CHROMIUM IONS ON TGF-BETA EXPRESSION AND MINERALIZATION OF BONE FORMING CELLS IN-VITRO}

S. Drynda ${ }^{1,2}$, A. Drynda ${ }^{1}$, J. Kekow ${ }^{2}$, C.H. Lohmann ${ }^{1} .{ }^{1}$ Department of Orthopaedic Surgery, Magdeburg; ${ }^{2}$ Clinic of Rheumatology, Vogelsang, Germany

Background: Bone homeostasis is regulated at different levels. Transforming growth factor-beta (TGF- $\beta$ ) which exists in three isoforms in human and is stored in the latent form in the extracellular matrix is a major player in the regulation of osteoblast and osteoclast maturation, development, and function. The balance of bone formation and resorption is affected by numerous influences, such as hormone status, inflammation, and mechanical load.

In the aging population, supplied increasingly with artificial joint replacements, release of particles or ions from arthroplasty may exert local effects in the periprosthetic tissue. Cobalt and chromium ions are released through corrosion from metal-on-metal arthroplasty and modulate the gene expression level of several cytokines, chemokines and other mediators in bone cells.

Objectives: It was the aim of the study to analyse the effect of $\mathrm{Co}^{2+}$ and $\mathrm{Cr}^{3+}$ ions on the expression of TGF- $\beta$ isoforms in bone forming cells and their impact on mineralization.

Methods: The study investigated the effect of $\mathrm{Co}^{2+}$ and $\mathrm{Cr}^{3+}$ ions on the expression of TGF- $\beta 1-3$ in the human osteosarcoma cell lines (MG63 and SaOs2) and primary human osteoblasts.

Cells $\left(3 \times 10^{5}\right)$ were seeded in $2 \mathrm{ml}$ DMEM $(10 \% \mathrm{FCS})$ into 12 well plates and stimulated with $\mathrm{CoCl}_{2}$ and $\mathrm{CrCl}_{3}$ in concentrations between $50-250 \mu \mathrm{M}$ for 24 hours. Total RNA was extracted and changes of expression levels of TGF- $\beta 1-3$ were analysed by real-time PCR using sequence-specific primers and probes. For mineralization cells were cultivated for up to 4 weeks in DMEM $(10 \%$ FCS) supplemented with $0.2 \mathrm{mM}$ ascorbic acid, $10 \mathrm{~nm}$ dexamethasone and $10 \mathrm{mM}$ glycerophosphate and $\mathrm{Co}^{2+}$ and $\mathrm{Cr}^{3+}$. Calcium deposits were detected by $1 \%$ Alizarin Red S (pH 4.1) staining.

Results: The osteosarcoma cell lines as well as primary human osteoblasts isolated from bone explants expressed all three TGF- $\beta$ isoforms, with TGF- $\beta 1$ as most abundently expressed isoform. A dose dependent reduction of all TGF- $\beta$ isoforms by $\mathrm{Co}^{2+}$ ions was observed, the strongest effect was found for TGF- $\beta 2$. In MG63 cells and primary osteoblasts the mRNA levels of TGF- $\beta 2$ decreased to $15 \pm 4 \%$ and $17 \pm 15 \%$ compared to the unstimulated control. The effect was lesser in SaOs2 cells with a reduction to $61 \pm 7 \%$ compared to control. In contrast to bivalent $\mathrm{Co}$ ions, the trivalent $\mathrm{Cr}$ ions had no significant effect on the expression of all TGF- $\beta$ isoforms.

While $\mathrm{Co}^{2+}$ in a concentration range of 50-250 $\mu \mathrm{M}$ did not impair the mineralization, $\mathrm{Cr}^{3+}$ exerted a strong inhibitory effect on the mineralization in osteosarcoma cells and primary osteoblasts. In a dose dependent fashion mineralization was influenced already at concentrations of $50 \mu \mathrm{M} \mathrm{CrCl} 3$ and showed the strongest effect at $250 \mu \mathrm{M}$.

Conclusions: The results of our study show that bivalent cobalt ions and trivalent chromium ions have different effects on bone forming cells. While $\mathrm{Cr}^{2+}$ affects the expression of the different TGF- $\beta$ isoforms in osteoblast-like cells and primary osteoblasts, no inhibitory effect on mineralization in the tested concentrations was seen. $\mathrm{Cr}^{3+}$ however, did not influence the expression of TGF- $\beta$ but strongly inhibited the mineralization in vitro.

Our data implicate that the inhibitory effect of metal ions such as Co and $\mathrm{Cr}$ ions on the transcription of the bone regulating cytokines TGF- $\beta 1-3$ and on bone forming activity may influence bone homeostasis.

Acknowledgements: Study supported by Stiftung Endoprothetik (S01/16).

Disclosure of Interest: None declared

DOI: 10.1136/annrheumdis-2017-eular.6218

\section{AB0075 TARGETING IMMUNE AND NON-IMMUNO SYNOVITIS BY 1,3,5-TRIAZINE-THIAZOLE VIA DUAL INHIBITION OF NF-KB AND EGFR-TKS FOR POSSIBLE BENEFIT IN RHEUMATOID ARTHRITIS}

U.P. Singh ${ }^{1}$, J.K. Shrivastava ${ }^{1}$, A. Verma ${ }^{1}$, H.R. Bhat ${ }^{2} .{ }^{1}$ Department of Pharmaceutical Sciences, Sam Higginbottom University of Agriculture, Technology \& Sciences, Allahabad; ${ }^{2}$ Department of Pharmaceutical Sciences, Dibrugarh University, Dibrugarh, India

Background: Rheumatoid arthritis (RA) is a chronic inflammatory disease which is easily recognised by unrelenting inflammation, joint erosion, joint immobility and severe debilitation. The cause of the disease suggests that, T cells, B cells, macrophages, and dendritic cells gain access to the inflamed synovium causing progression of disease via generation of cytokines and autoantibodies. 